\title{
Las actitudes en el perfil de egreso: un reto para las instituciones educativas
}

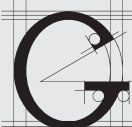

eneralmente, en los planes de estudio se contemplan conocimientos, habilidades y actitudes como elementos que conforman el perfil del egresado y que prácticamente se convierten en los objetivos de todo el proceso formativo. De la misma manera, en casi todos los planes de estudio resulta muy claro de qué manera se van a conseguir los conocimientos y las habilidades, para lo cual se estructuran cursos, seminarios, talleres, etcétera; sin embargo, no aparece con la misma claridad de qué forma los estudiantes conseguirán las actitudes que se pretenden. Por tanto, casi siempre el logro de actitudes se reduce a un buen deseo o, cuando mucho, a la suposición de que se van derivando automáticamente de los conocimientos y de las habilidades. El problema es que esto es discutible.

Es conveniente precisar qué se entiende, desde la investigación psicológica, por "actitud". Se trata de una disposición más o menos estable, solamente que tal disposición es la resultante de la integración de tres componentes: un componente cognoscitivo, un componente afectivo emocional y un componente conductual (Eagly, 1995).

El componente cognoscitivo se refiere al conjunto de conocimientos, creencias, saberes, convicciones, certezas, etcétera, que la persona acumula, organiza e integra en un cierto sistema. No es sólo la cantidad de información, sino la manera como tal información es asumida. Es decir, se va constituyendo en la cosmovisión de la persona, en aquello que ésta considera cierto y, en algunos casos, hasta verdadero. De hecho, tal cosmovisión le permite ver la realidad de una manera determinada.

El componente afectivo emocional tiene que ver con la atracción o repulsión que se experimenta en relación con cierta realidad. No siempre esa atracción o repulsión tiene una base racional, es decir, no siempre se deriva de la valoración que se hace acerca de la consistencia del componente cognoscitivo; sin embargo, ciertamente puede generarse un conflicto ante las discrepancias entre lo que se sabe y lo que se siente. Puede decirse que este componente constituye el tono emocional y afectivo de abordar la vida.

El componente conductual se refiere al comportamiento regular del sujeto ante las diferentes situaciones. Lo que suele hacer la persona. No tiene que ver estrictamente con lo que llamamos hábitos, puesto que no se trata de la automatización de una conducta, sino de la ejecución derivada de lo que se conoce y de lo que se siente en relación con algún aspecto de la realidad. Algunos investigadores como Joseph Nutin (1990) consideran que este componente es el indicador más fiable de la actitud. 
Para hablar, entonces, sobre desarrollar una actitud, habría que atender cada uno de sus componentes y su correspondiente integración. En muchos planes de estudio se espera que el egresado logre una actitud reflexiva y crítica. Esto nos invita a analizar las implicaciones que tendría en relación con cada uno de los componentes mencionados. ¿Cuál pudiera ser el estado del componente cognoscitivo de una actitud reflexiva y crítica? Pues bien, se proponen algunas hipótesis al respecto. En primer lugar, la reflexión misma debería ser ya una actividad habitual a la que, además, se le concediera un gran valor. La reflexión en sentido estricto es ya posible a partir de los inicios de la adolescencia. Por tanto, durante la formación universitaria pensar reflexivamente debería ser una actividad totalmente ordinaria.

Hay que precisar entonces qué se entiende por reflexión, a fin de detectar en qué nivel de logro es previsible identificarla durante los tiempos de estudiante. La reflexión puede entenderse como la acción mental que permite atender detenidamente cualquier proceso de razonamiento y regresar sobre el mismo para verificar aciertos o errores y, por tanto, fundamentar convicciones, toma de decisiones o ejecución de conductas determinadas. Esta actividad mental permite también hacer consciente la conciencia, valga la aparente redundancia, e incrementar la clarificación de la identidad personal.

En este sentido, el desarrollo de este componente actitudinal supone, además de acumular y organizar conocimientos y creencias, la clarificación cada vez mayor de la propia identidad. Es decir, en la medida que se sabe más de las disciplinas que se estudian, se sabe también más de sí mismo como sujeto afectado por la disciplina. En otras palabras, entre más saberes posean los alumnos en relación con lo que estudian, al mismo tiempo más sabrán de sí mismos como profesionales potenciales de ese campo, de tal manera que se vaya consiguiendo una completa sintonía entre lo que el quehacer profesional demanda y lo que las aspiraciones personales pretenden. Así, se puede garantizar la realización de la persona y evitar, o al menos disminuir, cualquier riesgo de crisis de identidad.

Pero además, en los planes de estudio se pretende desarrollar una actitud reflexiva y crítica. Puede entenderse que se trata de una actividad de juicio ante la realidad y ante sus diversas explicaciones, que se supere la ingenui- dad infantil y el egocentrismo adolescente, que los juicios sean cada vez más fundados y que sea capaz de reconocer el valor y la bondad independientemente de los propios gustos. Por último, que los juicios también estén orientados a evaluar las convicciones, las emociones y las acciones propias, de tal manera que se supere cualquier dogmatismo tanto personal como impuesto por el medio. Lo anterior no quiere decir que se caiga en un escepticismo a ultranza, sino que se mantenga una disposición siempre analítica que permita tomar decisiones y obrar en consecuencia. Tal vez este elemento de la reflexión crítica sea uno de los logros que más tarden en conseguirse, no sólo por la tardanza en el desarrollo intelectual, sino porque las instituciones muchas veces contribuyen con su sobreprotección a que los sujetos en formación demoren mucho en conseguir su autosuficiencia.

¿Cómo interviene el componente emocional afectivo en el logro de una actitud reflexiva y crítica? Originándola y manteniéndola. El gusto por la reflexión no es precisamente natural. Tal vez nos damos cuenta de que cualquier llamado a pensar no es recibido con mucho entusiasmo en general, menos aún en un mundo como el nuestro, que evita con tanta facilidad la reflexión y se inclina más por el activismo o, cuando mucho, por el recurso de las imágenes y los estímulos sonoros. Por tanto, el gusto por la reflexión hay que aprenderlo también y se aprende en la medida en que se disfruta y poco a poco, como cualquier otra actividad compleja. Pero una vez aprendido, puede impulsar el inicio de la reflexión y el que ésta se mantenga.

Ahora bien, existe otra situación para considerar, la conducta como manifestación evidente de la actitud. ¿Qué tanto se reflexiona? ¿De qué manera se recibe la información venida del maestro, del libro o de cualquier fuente? ¿Cuánto tiempo se dedica a reflexionar sobre sí mismo, sobre el quehacer actual del estudiante, sobre el futuro ejercicio profesional? Se supone que la actividad de reflexionar, como una actividad cotidiana, debiera derivarse de la convicción de que reflexionar es bueno y de la emoción que su ejercicio comporta. El problema es precisar qué se hace para conseguirlo. ¿Qué estamos haciendo los maestros para que se formen con una actitud reflexiva y crítica? ¿Cuestionamos, confrontamos, originamos conflictos cognitivos, estimu- 
lamos la discusión, reforzamos el pensamiento independiente, valoramos preferentemente el razonamiento a la simple repetición reproductiva, prescindimos de nuestra suficiencia para atender el proceso y la manera de pensar del estudiante?

El problema es que no se precisa en los planes de estudio ni dónde, ni cuándo ni de qué manera se van a originar y desarrollar las actitudes que se desea en el perfil de egreso. Indudablemente que esto representa un reto para las instituciones educativas que no se resuelve con algunos cursos. Es inobjetable que las actitudes resultan de la interacción con los otros. Si los estudiantes se incorporaran a una institución educativa en la que se vivieran las actitudes que se desean para sus egresados, el problema dejaría de ser tal.

Retomando el análisis inicial, es indudable que una de las cosas que se requiere es el conocimiento. Pero es ingenuo pensar que basta con que se sepa algo sobre alguna cosa para que ya por ese solo hecho se tenga una actitud formada. En ese caso debería ser suficiente el conocimiento sobre la ley y sus bondades para que se consiguiera una actitud de cumplimiento de la misma, y la experiencia nos dice lo contrario. No basta sólo el conocimiento, pues; en este mismo terreno, es necesario que tal conocimiento se integre en el sistema global de creencias, de tal manera que forme parte del mismo y dentro de éste tenga sentido. Se ha podido precisar que ningún conocimiento es indiferente para la vida emotiva de la persona, más aún, la emoción de alguna manera es la tonalidad del conocimiento. Hay conocimientos que nos emocionan y que nos provocan cierta repulsa. Aquí sería interesante revisar qué tan atractivos han sido los conocimientos que durante su carrera han ido construyendo los estudiantes. Porque esto sería una garantía de que se mantendrán como parte del sistema de creencias en relación con el quehacer profesional.

\section{Consideraciones finales}

Dado que el componente conductual es el más confiable en la manifestación y en la formación de las actitudes, lo primero que hay que afirmar es que "a reflexionar se aprende reflexionando", de la misma manera que a nadar se aprende nadando. Si esto es así, entonces se tienen que propiciar mayores oportunidades de reflexionar, se tienen que reforzar, para que se incrementen, las manifestaciones de reflexión, se tiene que valorar la reflexión de una forma privilegiada sobre cualquier otra actividad meramente repetitiva, mecánica, especialmente en relación con el uso de las casi milagrosas tecnologías que, en muchas ocasiones, han suplantado la acción inteligente y pensante de profesores y estudiantes $\mathrm{y}$, sin negar que un ambiente favorable para la reflexión pudiera ser propiciado por el trabajo de los profesores, es indispensable que los estudiantes no lo esperen pasivamente, que lo construyan con la reflexión personal frecuente, con la creación de círculos de discusión y análisis sobre asuntos profesionales o cualquier otro tema, con lecturas compartidas, con la elaboración de ensayos en los que se plasme su pensamiento, etcétera. Lo mismo puede decirse en relación con la "reflexión crítica". Todos necesitamos una reflexión más juiciosa, en el sentido de que posea un nivel de análisis de mayor profundidad. Estamos cansados tanto de las banalidades como del criticismo destructivo. Conseguir esta actitud también requiere multiplicar las ocasiones de analizar, de ver más allá de lo obvio, de buscar las causas o razones que intervienen en los fenómenos, examinar consecuencias, prever situaciones posibles, etcétera. Como se puede ver, de lo que se debe estar más alejado es de la pasividad y del conformismo.

http://www.pcs.org/assets/uploads/brain(1).jpg

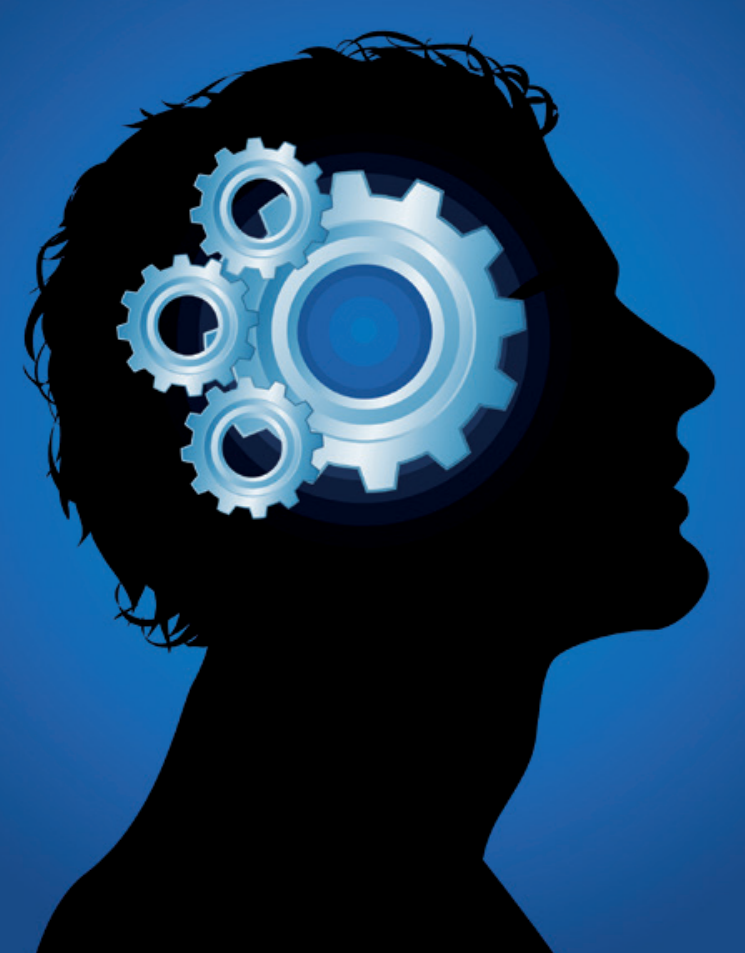


El proceso de formación académica, por sí mismo, parece que no ha sido capaz de transformar la conciencia de las personas para que rebasen la visión meramente laboral o de privilegio social. La mayoría de los estudiantes egresan con la idea de haber sido formados para trabajar en un ámbito determinado y no tanto para vivir de otra manera. Puede suponerse que los planes de estudio no dan para otra cosa. Para contrarrestar esta situación se requiere una disposición personal diferente: más abierta a la transformación positiva. Es indispensable romper el tedio, la rutina, la pasividad, y responsabilizarse más de la propia formación, esto implica saberse comprometido consigo mismo para la vida y no sólo para una labor específica. En la medida en que se vaya dando una acción de fuera hacia dentro y de dentro hacia fuera, entre la persona y el entorno educativo, se podrá ir garantizando la construcción de la identidad personal, dentro de la cual la práctica específica de una profesión sólo representa un subconjunto de la misma.

\section{Fuentes de consulta}

Eagly, A.H. y Chaiken, S. (1995). Attitude strength, attitude structure and resistance to change. En Petty, R.E. y Krosnick, J.A. (Eds.), Attitude strength: antecedents and consequences. Mahwah, N. J.: LowrenceErlbaum.

Nuttin, J. (1990). La ilusión de cambiar la actitud: hacia una teoría del contagio de respuesta de la persuasión. Nueva York: Academic Press. 